\title{
Analisis Kebutuhan LKS Berbasis STEM kelas XI Materi Fluida Dinamis
}

\author{
${ }^{\mathbf{1}}$ Nurul Komariyah, ${ }^{2}$ Hadma Yuliani, ${ }^{3}$ Nur Inayah Syar \\ ${ }^{1,2,3}$ Program Studi Tadris Fisika Jurusan MIPA IAIN Palangka Raya \\ Email Korespondensi: nurulkoma06@gmail.com, hadma.yuliani@iain-palangkaraya.ac.id, \\ nur.inayah.syar@iain-palangkaraya.ac.id
}

\begin{tabular}{|c|c|}
\hline Article Info & \\
\hline $\begin{array}{l}\text { Article History } \\
\text { Received: } 12 \text { Nov } 2021 \\
\text { Revised: } 29 \text { Dec } 2021 \\
\text { Published: } 30 \text { Dec } 2021 \\
\end{array}$ & \multirow{2}{*}{$\begin{array}{l}\text { This research was conducted to complete the teaching materials, namely the } \\
\text { worksheets used by teachers. This research is also based on the lack of use of } \\
\text { student worksheets in SMA Negeri } 5 \text { Palangka Raya. Teachers often use } \\
\text { textbooks and modules in the learning process rather than using student } \\
\text { worksheets. The purpose of this study was to determine the needs of students } \\
\text { for the use of STEM-based student worksheets in class XI on dynamic fluid } \\
\text { material. The research instrument used was a questionnaire distributed to } \\
\text { students via google form. Based on the results of the needs analysis, } 74.1 \% \text { of } \\
\text { students stated that physics is difficult to learn and understand, because it uses } \\
\text { a lot of formulas. The online system is the main reason students have difficulty } \\
\text { understanding physics material. Teaching materials that are often used by } \\
\text { teachers in learning physics are textbooks. Student modules and worksheets } \\
\text { are used very rarely and have a fairly low percentage of } 33.3 \% \text { and } 25.9 \% \text {, } \\
\text { respectively. Therefore, it is necessary to develop STEM-based worksheets on } \\
\text { dynamic fluid materials. }\end{array}$} \\
\hline $\begin{array}{l}\text { Keywords } \\
\text { Dynamic fluid material, } \\
\text { LKS, Science Technology } \\
\text { Engineering Mathematics, } \\
\text { STEM. }\end{array}$ & \\
\hline Informasi Artikel & Abstrak \\
\hline $\begin{array}{l}\text { Kata kunci } \\
\text { LKS, materi fluida } \\
\text { dinamis, Science } \\
\text { Technology Engineering } \\
\text { Mathematics, STEM. }\end{array}$ & $\begin{array}{l}\text { Penelitian ini dilakukan untuk melengkapi bahan ajar yaitu LKS yang } \\
\text { digunakan oleh guru. Penelitian ini juga didasari karena kurangnya penggunaan } \\
\text { bahan ajar lembar kerja siswa di SMA Negeri } 5 \text { Palangka Raya. Guru lebih } \\
\text { sering menggunakan buku paket dan modul dalam proses pembelajarannya } \\
\text { daripada menggunakan lembar kerja siswa. Tujuan dari penelitian ini adalah } \\
\text { untuk mengetahui kebutuhan peserta didik terhadap penggunaan lembar kerja } \\
\text { siswa berbasis STEM di kelas XI pada materi fluida dinamis. Instrumen } \\
\text { penelitian yang digunakan yakni angket yang disebarkan kepada peserta didik } \\
\text { melalui googleform. Berdasarkan hasil analisis kebutuhan terdapat } 74,1 \% \\
\text { peserta didik menyatakan bahwa pelajaran fisika sulit untuk dipelajari dan } \\
\text { diphami, karena banyak menggunakan rumus-rumus. Sistem daring menjadi } \\
\text { alasan utama peserta didik kesulitan dalam memahami materi fisika. Bahan ajar } \\
\text { yang sering digunakan guru dalam pembelajaran fisika adalah buku teks. } \\
\text { Modul dan lembar kerja siswa sangat jarang digunakan dan memiliki } \\
\text { persentase yang cukup rendah yaitu 33,3\% dan 25,9\%. Maka dari itu } \\
\text { diperlukan adanya pengembangan LKS berbasis STEM pada materi fluida } \\
\text { dinamis. }\end{array}$ \\
\hline
\end{tabular}




\section{PENDAHULUAN}

Kurikulum adalah salah satu bentuk perkembangan guru yang menjadi acuan dalam proses pembelajaran dan disesuiakan dengan perkembangan pembelajaran. Kurikulum 2013 adalah langkah lanjutan dari kurikulum sebelumnya (Trianto, 2007). Menurut Hidayat (2013) bahwa kurikulum 2013 itu terjadi adanya peningkatan dan keseimbangan antara kompetensi sikap (attitude), keterampilan (skill), dan pengetahuan (knowledge). Menurut Mulyasa (2014) Kurikulum satuan pendidikan bersifat aktif yaitu adanya perubahan dan perkembangan yang menyesuaikan tantangan perkembangan. Meskipun begitu, yang harus dilakukan yakni visi dan arahnya yang jelas (Mustafa \& Dwiyogo, 2020). Kurikulum 2013 ini sebagai langkah awal dalam upaya meningkatkan kualitas guru (Trianto, 2007). Upaya peningkatan kualitas guru yang berkaitan dengan tugas pokok dan fungsinya guru sangat berperan penting, hal tersebut tertuang pada Permendikbud Tahun 2016 tentang Standar Proses Pendidikan Dasar yang menyatakan bahwa guru harus melakukan perencanaan pembelajaran, pelaksanaan proses pembelajaran serta penilaian proses pembelajaran untuk meningkatkan efisiensi dalam ketercapaian lulusan. Menurut No 22 Tahun 2016 tentang Standar Proses Pendidikan, upaya peningkatan kualitas guru diterapkan dalam semua mata pelajaran dan salah satunya adalah pembelajaran fisika

Fisika adalah ilmu yang aspek penalaran dan penerapannya sangat penting dalam upaya penguasaan ilmu pengetahuan dan teknologi. Fisika erat kaitannya dengan pendekatan saintifik. Pendekatan saintifik ini memperluas wawasan dan pengetahuan, meningkatkan keterampilan ilmiah, dan kepedulian pada produk melalui teori maupun prinsip-prinsipnya. Oleh karena itu, fisika harus dipahami betul sehingga peserta didik-peserta didik dapat meningkatkan kemampuan dan keterampilannya dalam menyelesaikan berbagai masalah yang dihadapi (Agustina, 2017).

Pembelajaran fisika harus direncanakan dan dipersiapkan dengan sangat baik agar tujuan pembelajaran tercapai. Salah satu bentuk perencanaan pembelajaran fisika ialah dengan mempersiapkan bahan ajar. Bahan ajar sangat dibutuhkan untuk mendukung pencapaian tujuan pembelajaran (Kemendikbud, 2013). Bahan ajar ialah alat untuk melaksanakan proses yang memungkinkan guru dan peserta didik melakukan suatu kegiatan belajar mengajar (Zuhdan, 2011). Bahan ajar menjadi pegangan bagi guru/dosen dalam melakukan pembelajaran baik di kelas, laboratorium, atau luar kelas. Dalam Permendikbud (2013) mengatakan bahwa penyusunan bahan ajar merupakan bagian dalam proses belajar mengajar. Dalam proses pembelajaran, penyajian bahan ajar menjadi kompetensi utama seorang guru dalam mendesain aktivitas dan kemampuan berpikir seperti apa yang harus dikuasai peserta didik (Susilawati \& Khoiri, 2015).

Mengatasi hal tersebut perlu dikembangkan kemampuan pada diri peserta didik yakni, pembelajaran yang berkaitan dengan sains, teknologi, teknik dan matematika yang jarang sekali guru berikan (Mastang, 2017). Keterampilan pembelajaran tersebut dapat didorong dengan adanya proses pembelajaran yang dapat membuat peserta didik aktif khususnya yang berkaitan proses pembelajaran dengan sains, teknologi, teknik dan matematika. Hal ini bisa dilakukan dengan adanya perencanaan pembelajaran, oleh karena itu diperlukan bahan ajar peserta didik dalam proses pembelajaran tersebut. Agar memiliki nilai kegunaan lebih, maka di buat bahan ajar lembar kerja peserta didik yang berbasis sains, teknologi, teknik dan matematika agar menarik dan memotivasi peserta didik. Sehingga, dengan adanya lembar 
kerja peserta didik berbasis sains, teknologi, teknik dan matematika dapat menarik minat dan motivasi peserta didik dalam mempelajari fisika (Nidyasafitri et al., 2017).

Sebelum mengembangkan LKS, peneliti harus menggali terlebih dahulu tingkat kebutuhan target pengguna LKS di sekolah yang akan menggunakan lembar kerja tersebut. Kebutuhan LKS tercermin dari sistem pembelajaran online yang diterapkan membuat siswa merasa kesulitan dalam proses pembelajaran, khususnya dalam mempelajari materi fisika (Vitrianingsih et al., 2021), sehingga kehadiran bahan ajar alternatif akan sangat membantu terlaksananya pembelajaran dengan baik. Dalam proses pengembangan bahan ajar menggunakan model ADDIE, pada tahap pertama yakni pendefinisian, salah satu bagian utamanya yaitu dilaksanakannya analisis kebutuhan (Andila et al., 2021; Fitriani, 2017).

\section{METODE}

Penelitian ini adalah penelitian deskriptif kuantitatif. Menurut Russeffendi (2010) mengatakan bahwa penelitian deskriptif adalah adalah penelitian yang menggunakan observasi, wawancara atau angket dan mengenai subjek yang sedang kita teliti. Sugiyono (2017) mengatakan bahwa, penelitian kuantitatif deskriptif yaitu penelitian yang dimanfaatkan untuk analisis data yang sudah dikumpulkan dalam bentuk gambaran atau deskripsi.

Metode penelitian yang digunakan metode survei. Pengumpulan data dalam penelitian ini yaitu melalui penyebaran angket dengan menggunakan google form. Subjek penelitian dalam penelitian ini adalah peserta didik di kelas XI SMAN 5 Palangka Raya yang berjumlah 27 orang. Data dianalisis secara deskriptif dan disajikan dalam bentuk diagram lingkaran.

\section{HASIL DAN PEMBAHASAN}

Hasil wawancara dengan guru fisika di SMAN 5 Palangka Raya hasil yang didapatkan yaitu banyak peserta didik yang mengatakan mata pelajaran fisika termasuk mata pelajaran yang sulit, dan untuk materi fisika yang cenderung sulit adalah materi fluida dinamis. Peserta didik juga mengatakan bahwa guru jarang menggunakan bahan ajar berupa LKS, akan tetapi guru lebih sering menggunakan bahan ajar buku paket dan modul.

Penelitian dilakukan secara online dengan cara menyebarkan angket analisis kebutuhan dalam bentuk google form untuk peserta didik kelas XI di SMAN 5 Palangka Raya. Menurut peserta didik pelajaran fisika cenderung sulit hal ini di dukung oleh Widiadnyana et al., (2014) yang menyatakan bahwa fisika pembelajaran yang sulit dan sering dibenci oleh peserta didik karena banyak menggunakan rumus dan sulit dipahami. Kesulitan peserta didik mengenai pembelajaran fisika digambarkan pada diagram berikut: 


\section{Menurut kamu, apakah mata} pelajaran fisika termasuk pelajaran yang sulit?

27 jawaban

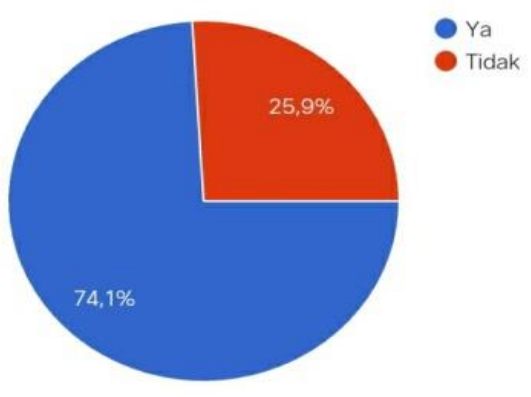

Gambar 1. Digram respons peserta didik untuk pembelajaran fisika yang sulit

Diagram pertama, menunjukkan presentase sebanyak 74,1\% menyatakan bahwa pembelajaran fisika sulit. Kesulitan yang dialami peserta didik dalam pembelajaran fisika yaitu banyaknya menggunakan rumus dan sulit untuk dipahami. Mata pelajaran fisika yang menurut peserta didik sulit ialah mata pelajarn fisika fluida dinamis. Hal ini dapat dilhat dari diagram dibawah ini:

2. lihlah salah satu materi yang menurut kamu sulit?

27 jawaban

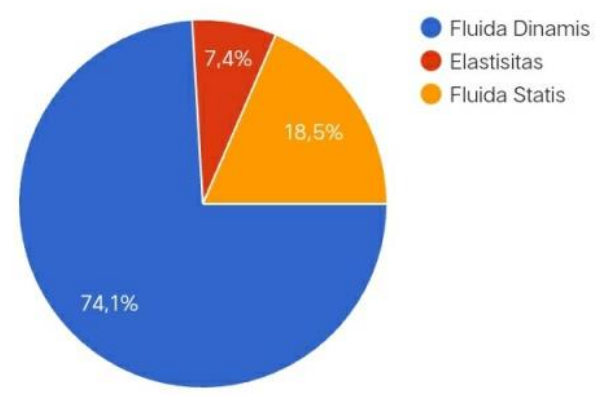

Gambar 2. Diagram materi fisika yang sulit

Berdasarkan diagram kedua, sebanyak $74,1 \%$ peserta didik menyatakan bahwa fluida dinamis merupakan materi yang sulit. Peneliti sudah memberikan dua pilihan yaitu materi elastisitas dan fluida statis akan tetapi peserta didik banyak memilih bahwa materi flida dinamis. Hal ini tentunya sangat berpengaruh terhadap proses pembelajarn peserta didik karena sebaiknya ada bahan ajar yang menunjang dan menarik agar peserta didik dapat mudah memahami (Arofah \& Cahyadi, 2019). Hal ini juga tentunya memerlukan bahan ajar yang menarik dan mudah dipahami agar peserta didik mudah dalam memahami materi dalam 
prroses pembelajaran (Septiani \& Setyowati, 2020). Adapun bahan ajar yang apat digunakan peserta didik agar dapat menarik perhatian dan mudah dipahami adalah sebagai berikut:

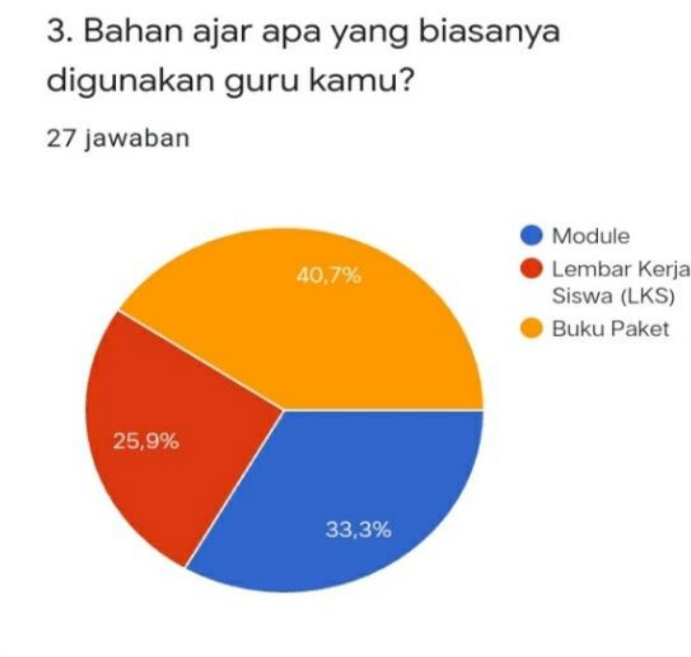

Gambar 3. Diagram bahan ajar yang biasanya digunakan guru

Berdasarkan diagram ketiga diatas menunjukkan bahwa guru lebih sering menggunakan bahan ajar buku paket dan modul dalam proses pembelajaran dengan prsentase memilih buku paket sebanyak 40,7\%, yang memilih modul sebanyak 33,3\% dan yang memilih lembar kerja peserta didik sebanyak 26,9\%. Dapat disimpulkan bahwa penggunaan LKS jarang digunakan oleh guru. Penggunaan LKS dalam proses pembelajaran yang mudah dipahami bagi peserta didik (Asmirani et al., 2013) Hal ini menjadi solusi yang dapat ditawarkan untuk mengatasi maslaah tersebut. Hal ini dapat dilihat pada diagram berikut ini:
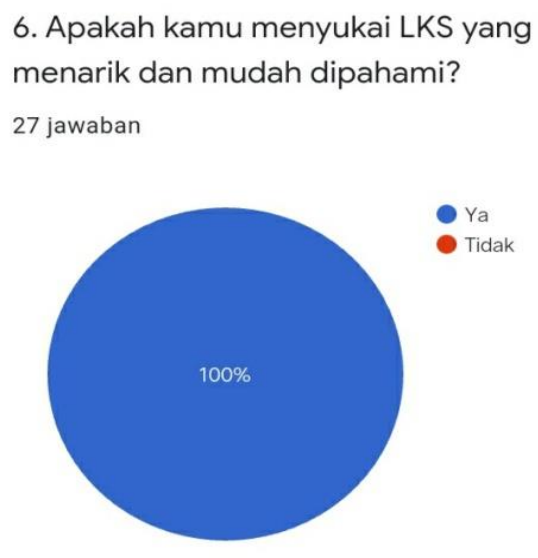

Gambar 4. Diagram tentang menyukai LKS yang mudah dan menarik

Berdasarkan diagram keempat diatas menunjukkan bahwa sebanyak presentase $100 \%$ peserta didik menyukai LKS yang mudah dipahami dan menarik. Karena, peserta didik cenderung suka yang tidak terlalu monoton dan dapat dengan mudah dan dapat dipahami. LKS tidak hanya berisikan soal-soal, tetapi juga berisikan praktikum-praktikum sederhana yang menarik dan mudah dipahami peserta didik (Fahmidani et al., 2018). LKS yang mudah 
juga LKS yang berisikan materi yang mengarahkan ke beberapa aspek, seperti mengaitkan kepada sains, teknlogi, teknik, dan matematika. Hal ini dapat menarik peserta didik dalam melakukan kegiatannya. Ini dapat menjadi solusi untuk mengatasi masalah tersebut. Adapaun diagramnya sebagai berikut:
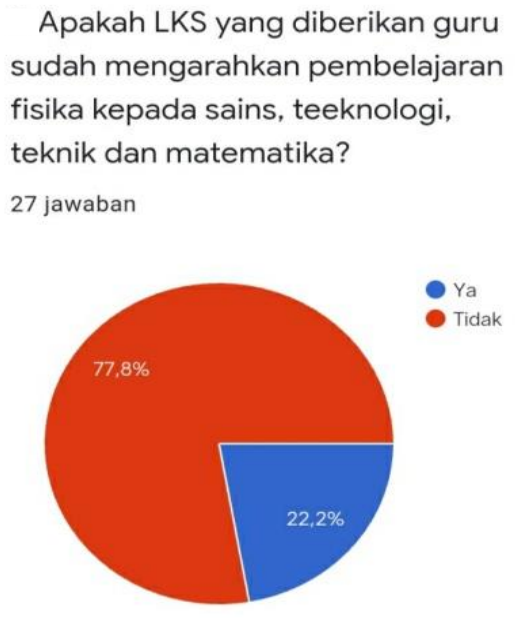

Gambar 5. Diagram LKS yang diberikan guru belum mengarahkan kepada STEM

Berdasarkan diagram 5 diatas menunjukkan bahwa LKS yang diberikan guru belum mengarahkan pembelajaran sains, teknologi, teknik dan matematika sebanyak presentase 77,8\%. Maka dari itu, peneliti memberikan solusi dan tawaran untuk mengembangkan LKS yang mengarahkan pembelajaran sains, teknologi, teknik dan matematika kepada peserta didik. Selain menarik, LKS yang peneliti buat juga mudah diapahmi. Hal ini menunjukkan bahwa peserta didik membutuhkan lembar kerja peserta didik yang berbasis sains, teknologi, teknik dan matematika, adapun respon peserta didik untuk mengembangkan LKS berbasis sains, teknologi, teknik dan matematika sebagai berikut:
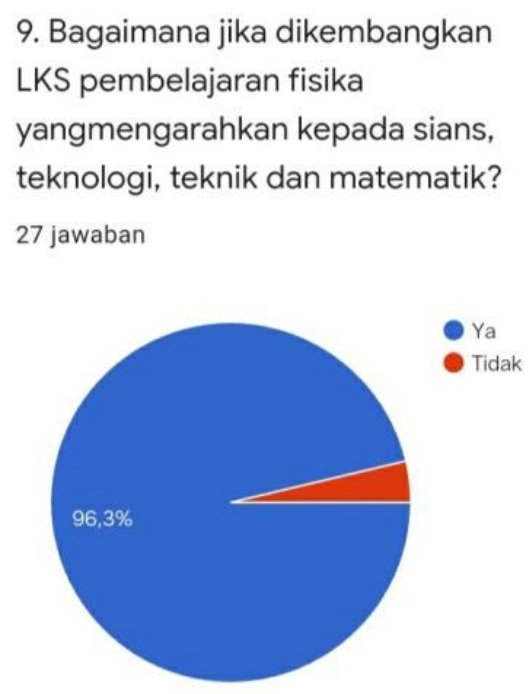

Gambar 6. Diagram Respons peserta didik terhadap dikembangkan LKS 
Diagram keenam menunjukkan sebanyak 96,3\% yang menyatakan memerlukan pengembangan LKS berbasis sains, teknologi, teknik dan matematika. LKS ini dapat membantu peserta didik memahami materi fluida dinamis yang banyak sekali manfaat penerapan dalam kehidupan sehari-harinya (Nidyasafitri et al., 2017).

\section{KESIMPULAN}

Hasil penyebaran angket secara online didapatkan kesimpulan yaitu pembelajaran pada saat ini (pandemi) cenderung sulit, dan peserta didikpun mengalami kendala. Kendalanya berdampak pada proses pembelajaran yang dialami peserta didik khusunya pembelajaran fisika. Sebanyak $74,1 \%$ peserta didik menyatakan bahwa pelajaran fisika sulit untuk dipelajari dan diphami, karena banyak menggunakan rumus-rumus, sistem daring menjadi alasan utama peserta didik dalam memahami materi fisika. Bahan ajar yang sering digunakan guru dalam pembelajaran fisika adalah buku paket. Modul dan LKS sangatlah jarang digunakan dan memiliki nilai terendah yaitu $33,3 \%$ dan $25,9 \%$. Maka dari itu diperlukan adanya pengembangan LKS berbasis STEM pada materi fluida dinamis.

\section{DAFTAR PUSTAKA}

Agustina, K. (2017). Pengembangan Lembar Kerja Peserta Didik (LKPD) Fisika Berbasis Inkuiri pada Materi Fluida Dinamis untuk Peserta Didik Kelas XI IPA di SMA Negeri 3 Sungguminasa.

Andila, K., Yuliani, H., Syar, N. I., Tadris, P., Raya, P., \& Tengah, K. (2021). Pengembagan Bahan Ajar Fisika Berbentuk E-Modul Berbasis Kontekstual Menggunakan Aplikasi eXe-Learning Pada Materi Usaha dan Energi. Kappa Journal, 5(1), 68-79. https://doi.org/10.29408/KPJ.V5I1.2757

Arofah, R., \& Cahyadi, H. (2019). Pengembangan Bahan Ajar Berbasis Addie Model. Halaqa: Islamic Education Journal, 3(1), 35-42. https://doi.org/10.21070/HALAQA.V3I1.2124

Asmirani, U., Putra, A., \& Asrizal, D. (2013). Pengaruh LKS Berbasis Sains Teknologi Masyarakat Terhadap Kompetensi Siswa Dalam Pembelajaran IPA Fisika di Kelas VIII SMPN 1 Kubung Kabupaten Solok. Pillar Of Physics Education, 1(1), 85-90. https://doi.org/10.24036/495171074

Fahmidani, Y., Andayani, Y., Srikandijana, J., \& Purwoko, A. A. (2018). Pengaruh Model Pembelajaran Berbasis Masalah dengan Media Lembar Kerja Terhadap Hasil Belajar Siswa SMA. Jurnalfkip.Unram.Ac.Id. https://doi.org/10.29303/cep.v2i1.1120

Fitriani, S. N. (2017). Pengembangan modul fisika berbasis sets untuk memberdayakan kemampuan berpikir kritis siswa. Kappa Journal, I(2), 32-44. http://ejournal.hamzanwadi.ac.id/index.php/kpj/article/view/Fitriani

Hidayat, S. (2013). Kesiapan Guru Menyongsong Kurikulum 2013. http://www.untirta.ac.id/berita-501-artikel-kesiapan-guru-menyongsong-kurikulum2013.html 
Kemendikbud. (2013). Permendikbud No. 65 tentang Standar Penilaian Pendidikan. Kementerian Pendidikan dan Kebudayaan.

Mastang, M. (2017). Pengembangan Perangkat Pembelajaran Berbasis Problem Based Learning Kelas X MIA I SMA Muhammadiyah Limbung. http://repositori.uinalauddin.ac.id/7531/

Mustafa, P. S., \& Dwiyogo, W. D. (2020). Kurikulum Pendidikan Jasmani, Olahraga, dan Kesehatan di Indonesia Abad 21. JARTIKA Jurnal Riset Teknologi Dan Inovasi Pendidikan, 3(2), 422-438. https://doi.org/10.36765/jartika.v3i2.268

Nidyasafitri, F., Serevina, V., Rustana, C. E., Fisika, J., Matematika, F., Pengetahuan, I., Universitas, A., Jakarta, N., Muka, J. R., No, R., \& Timur, J. (2017). Pengembangan Lks Berbasis Pbl (Problem Based Learning) Pada Pokok Bahasan Momentum Dan Impuls Fisika Sma Kelas XI. WaPFi (Wahana Pendidikan Fisika), 2(2), 51-57. https://doi.org/10.17509/WAPFI.V2I2.8279

Russeffendi, H. E. T. (2010). Perkembangan Pendidikan Matematika. Universitas Terbuka. https://scholar.google.com/scholar?hl=id\&as_sdt=0\%2C5\&q=Russeffendi\%2C+H.E.T. +2010.+Perkembangan+Pendidikan+Matematika.+Jakarta\%3A+Universitas+Terbuka.\& btnG=

Septiani, E., \& Setyowati, L. (2020). Penggunaan Media Pembelajaran Secara Daring Terhadap Pemahaman Belajar Mahasiswa. Prosiding Seminar Nasional Pascasarjana Universitas Negeri Jakarta. http://journal.unj.ac.id/unj/index.php/semnasps/article/view/16860

Sugiyono. (2017). Metode Penelitian Kuantitatif, Kualitatif, dan R\&D. CV. Alfabeta.

Susilawati, \& Khoiri, N. (2015). Pengembangan Bahan Ajar Fisika Bermuatan Lifeskill Untuk Siswa SMA (Halaman 86 s.d. 89). Jurnal Fisika Indonesia, 18(54), 86-89. https://doi.org/10.22146/jfi.24379

Trianto. (2007). Model-model Pembelajaran Inovatif Berorientasi Kontruktivistik. Prestasi Pustaka.

Vitrianingsih, D., Yuliani, H., Syar, N. I., Nasir, M., Agama, I., Negeri, I., \& Raya, P. (2021). Analisis Kebutuhan Pengembangan Lembar Kerja Siswa (Lks) Berbasis Problem Based Learning Pada Materi Elastisitas Dan Hukum Hooke Kelas Xi Di Sma Negeri 1 Palangka Raya. Karst: Jurnal Pendidikan Fisika Dan Terapannya, 4(1), `1-7. https://doi.org/10.46918/KARST.V4I1.981

Widiadnyana, I., Sadia, I., \& Suastra, I. (2014). Pengaruh Model Dicovery Learning Terhadap Pemahaman Konsep IPA dan Sikap Ilmiah siswa SMP. Jurnal Pendidikan Dan Pembelajaran IPA Indonesia, 4(2). https://ejournalpasca.undiksha.ac.id/index.php/jurnal_ipa/article/view/1344 
Zuhdan. (2011). Pengembangan Perangkat Pembelajaran Sains Terpadu Untuk Meningkatkan Kognitif, Keterampilan Proses Kreativitas serta Menerapkan Konsep Ilmiah Peserta Didik SMP. Program Pascasarjana UNY. https://scholar.google.com/scholar?hl=id\&as_sdt=0\%2C5\&q=zuhdan+Pengembangan+ Perangkat+Pembelajaran+Sains+Terpadu+Untuk+Meningkatkan+Kognitif\%2C+Ketera mpilan+Proses+Kreativitas+serta+Menerapkan+Konsep+Ilmiah+Peserta+Didik+SMP.+ \&btnG $=$ 